\title{
Autopsy and pre-mortem diagnostic discrepancy review in an Irish tertiary PICU
}

\author{
Mark O'Rahelly $^{1}$ D $\cdot$ Michael McDermott ${ }^{2} \cdot$ Martina Healy $^{1}$ \\ Received: 12 April 2021 / Revised: 28 May 2021 / Accepted: 9 June 2021 / Published online: 17 June 2021 \\ (C) The Author(s), under exclusive licence to Springer-Verlag GmbH Germany, part of Springer Nature 2021, corrected publication 2021
}

\begin{abstract}
Our study had two objectives: (1) to review ante- and post-mortem diagnoses and assign a Goldman error classification and (2) establish autopsy rates within our centre. We performed a retrospective analysis of autopsies performed on patients who died in our paediatric intensive care unit (PICU) between November 13, 2012, and October 31, 2018. Medical and autopsy data of all patients was reviewed, and Goldman classification of discrepancy between ante- and post-mortem diagnoses was assigned. Our centre is a tertiary PICU, and we included all patients that died in PICU within the designated timeframe. Our results were as follows: 396 deaths occurred in PICU from 8329 (4.75\%) admissions. Ninety-nine (25\%) had an autopsy, 75 required by the coroner. All were included in the study. Fifty-three were male and 46 females. Fifty-three patients were transferred from external hospitals, 46 from our centre. Forty-one were neonates, 32 were $<1$ year of age, and 26 were $>1$ year of age. The median length of stay was 3 days. Eighteen were post-cardiac surgery, and three post-cardiac catheter procedure. Major diagnostic errors (class I/II) were identified in $14(14.1 \%), 2$ (2\%) class I, and $12(12.1 \%)$ were class II errors. Class III and IV errors occurred in $28(28.2 \%)$ patients. Complete concordance (class V) occurred in $57(57.5 \%)$ cases.

Conclusion: We conclude that the autopsy rate and the diagnostic discrepancy rate within our PICU are comparable to those previously reported. Our findings show the continuing value of autopsy in determining the cause of death and providing greater diagnostic clarity. Given their value, post-mortem examinations, where indicated, should be considered part of a physician's duty of care to families and future patients.
\end{abstract}

\section{What is Known:}

- Major diagnostic discrepancies (class I/II) in PICU have been reported at 20.2\%. (10)

- PICU autopsy rates have varied from 36 to $67 \%$ since 1994 with most recently reported rates in 2018 being $36 \%$ (6-9) $^{(6)}$

What is New:

- We report an Irish PICU major diagnostic discrepancy (class I/II) rates of $14.1 \%$ contributing further to reported discrepancy rates in PICU literature to date.

- This study contributes the Irish PICU post-mortem rate in a tertiary centre which was 25\% over an almost 6-year period.

Keywords Paediatric $\cdot$ ICU $\cdot$ Post-mortem · Goldman · Discrepancy

Communicated by Piet Leroy

Mark O'Rahelly

markorahelly@gmail.com

Michael McDermott

Michael.McDermott@olchc.ie

Martina Healy

martinahealy@hotmail.com

1 Department of Anesthesia and Critical Care, Children's Health Ireland at Crumlin, Dublin, Ireland

2 Department of Pathology, Children's Health Ireland at Crumlin, Dublin, Ireland

\section{Introduction}

Given the severity of illness managed in a PICU, deaths are inevitable. The majority of deaths amongst in-patients in our institution now occur in the PICU. Due to the complex nature of this cohort of patients, identifying all those factors that have contributed to a patient's death may prove challenging, as may arriving at an unambiguous single designation for the cause of death.

Credible medical post-mortem examinations were first performed over 300 years ago, and they continue to make a significant contribution in supporting legal, forensic, audit, clinical governance, teaching and research activities [1]. Despite advances in modern imaging and other modalities, diagnostic 
discrepancies are still identified at post-mortem. Post-mortem examination remains a particularly valuable tool for the identification and evaluation of pathologic processes in complex patients [2]. PICU autopsy rates have been reported between 20 and $36 \%$ which in part can be attributed to illness complexity $[3,4]$.

The Goldman criteria - first described in 1983-are a means of classifying a discrepancy occurring between anteand post-mortem diagnoses and are outlined in Table 1 [5]. Major diagnostic errors (class I/II) in PICU have been reported to be approximately $20 \%$, thus showing the necessity for continued advocacy for post-mortem examination within institutions [6].

The primary aim of this study was to compare both the premortem and post-mortem diagnoses assigning a Goldman classification to each individual case. The second aim was to review our centre's data and to determine the number of postmortem examinations performed and compare that against our demographic data (number of admissions, crude mortality rate, etc.).

\section{Materials and methods}

Our study took place in a tertiary referral paediatric intensive care unit (PICU) over 6 years from November 13, 2012, to October 31,2018, with an average of 1044 admissions per year. The unit accepts patients ranging from extreme prematurity to 16 years. It is one of only two PICUs in the Republic of Ireland and comprises a 15-bed general intensive care unit (ICU) and an 8-bed cardiac ICU. Extracorporeal life support (ECLS) is available in support of the cardiac program.

A retrospective analysis of patients who died in the PICU in Children's Health Ireland at Crumlin and subsequently had an autopsy performed was undertaken. We included all patients admitted from the introduction of electronic healthcare records - which came into effect in the PICU in November 2012-until October 2018. A list of referral sources and all patient data originating from the PICU was accessed for the period. A total of 100 patients met inclusion criteria. Electronic and paper-based medical notes were reviewed, and all demographic and clinical data were collected, including clinical diagnoses recorded at the time of death. Where patients were transferred into the unit, the correspondence and medical records that accompanied them were also reviewed. This information was then cross-referenced with the autopsy reports retrieved from the pathology department database. One case was excluded as due to the medicolegal nature of the case we did not have access to the post-mortem outcome. This left 99 cases to be analysed.

The information gathered included age, gestational age, if the patient had surgery, length of stay, referral source, underlying medical conditions, limitations of supportive care documented, immediate proximate cause of death, ante-mortem diagnosis and post-mortem findings and diagnosis. These information were then examined and discussed by a consultant paediatric intensivist, a consultant paediatric pathologist and an ICU senior registrar. This process resulted in the assignment of an agreed Goldman classification for each case (Table 1). All class V classifications were assigned by the consultant pathologist at the time of data entry if complete concordance of diagnoses was noted. For all other cases, the full group reviewed all ante-mortem diagnostic data and then reviewed post-mortem findings together in order to arrive at a consensus. This data then permitted the prevalence and pattern of diagnostic discrepancies to be described for our patient cohort.

\section{Results}

Over the 6-year period covered by the study, there were 8329 admissions to PICU, the demographics of which are outlined in Table 2. There were 396 PICU deaths during this period giving a mortality rate of $4.75 \%$. Of the 396 deaths, 99 (25\%) had an autopsy performed.

The mortality autopsy rate by age and admission source are summarised in Fig 1.

Of the patients undergoing post-mortem examination, 53 were male $(53.5 \%)$ and 46 females $(46.5 \%)$. External hospitals referred 53 of these patients, and 46 came from within our own hospital. Forty-one of the patients were neonates, 32
Table 1 Goldman classification

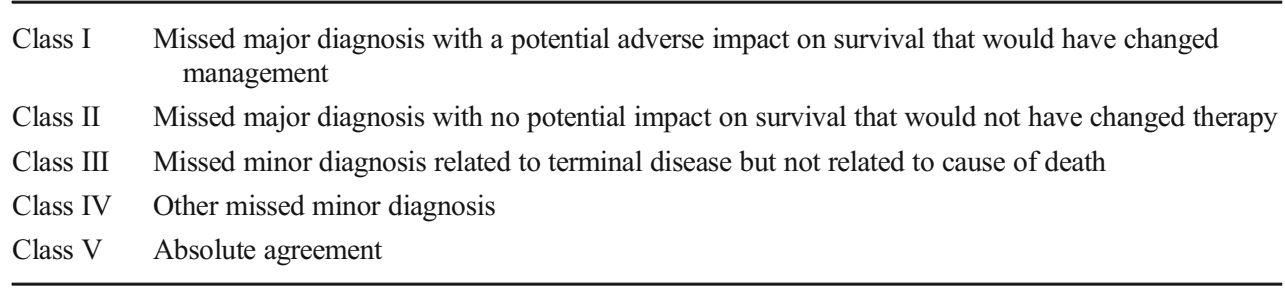


Table 2 Demographics of the admissions to PICU

\begin{tabular}{lll}
\hline Characteristic & All PICU admissions & PICU autopsy cohort \\
\hline Number (n) & 8329 & 99 \\
Sex (male) & $4578(54.9 \%)$ & $53(53.5 \%)$ \\
Age & $2302(27.6 \%)$ & \\
Neonates & $2431(29.1 \%)$ & $41(41.4 \%)$ \\
$<1$ year excluding neonates & 4 & $32(32.3 \%)$ \\
Median Length of stay (days) & & 3 \\
Admission source & $6349(76.2 \%)$ & \\
Same hospital & $1980(23.7 \%)$ & $46(46.4 \%)$ \\
External hospital & $3729(44.7 \%)$ & $53(53.5 \%)$ \\
Post-surgery & & $24(24.2 \%)$ \\
\hline
\end{tabular}

patients $>28$ days and $<1$ year of age and 26 patients $>1$ year of age. The median length of stay was 3 days. Seventy patients $(70.7 \%)$ had a pre-existing co-morbidity diagnosed at the time of death. Twenty-four of the patients were post-operative: 18 post-cardiac surgery, three post-cardiac catheter procedure and three post-"other" surgery. There were documented limitations of supportive care in place for 77 patients prior to their death in the ICU. Of the remaining patients, 21 died following delivery of conventional cardio-pulmonary resuscitation with one patient dying following discontinuation of extracorporeal resuscitation.

There was complete concordance between ante-mortem and post-mortem diagnoses in $57(57.5 \%)$ of our patients, corresponding to a Goldman class $\mathrm{V}$ designation. Two (2\%) class I discrepancies occurred: a post-mortem diagnosis of anomalous coronary artery and an unsuspected T cell leukaemia/lymphoma. Class II errors were identified in $12(12.1 \%)$ patients. More detail on these cases is outlined in Table 3. Class III accounted for $20(20.2 \%)$ of the cases and Class IV accounted for $8(8 \%)$. In the remaining case, we were unable to ascertain results for medico-legal reasons.

\section{Discussion}

Throughout its long history, post-mortem examination has remained the gold standard against which any ante-mortem clinical diagnosis is compared [7]. It continues to play a central role in the forensic analysis of unnatural death as well as representing an important tool for medical audit, underpinning the clinical governance of hospital services. Autopsies also provide opportunities for the teaching of medical, nursing and allied health professionals and continue to contribute towards research and the understanding of disease, as demonstrated most dramatically in the evaluations of recent deaths due to COVID-19 as caused by the novel coronavirus SARS-CoV-2 [8]. In certain cases, it also provides additional diagnoses, as per our data, class I-IV contributed information in 42 cases (42.4\%) which were unknown prior to the post-mortem results.

The focus of this study was to ascertain the number of autopsies undertaken on patients dying in our paediatric intensive care unit and to establish the contribution the autopsy made to the understanding of the patient's illness. The autopsy rate during the period of the study was $25 \%$ which is lower
Fig. 1 Incomplete datasets for indicated years

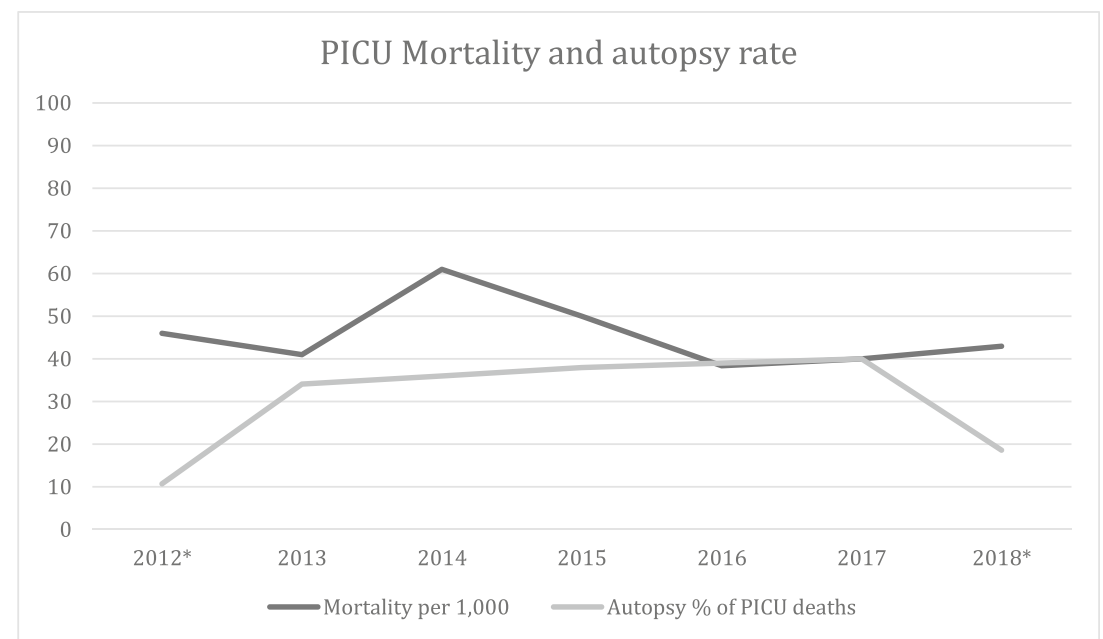


Table 3 Ante-mortem and post-mortem diagnoses of 14 patients and their corresponding Goldman classification

\begin{tabular}{|c|c|c|c|c|}
\hline Patient & Age & Ante-mortem diagnosis & Post-mortem diagnosis & $\begin{array}{l}\text { Goldman } \\
\text { classification }\end{array}$ \\
\hline $1(56)$ & 12 years & $\begin{array}{l}\text { Cardiac arrest query ventricular fibrillation due } \\
\text { to myocarditis }\end{array}$ & $\begin{array}{l}\text { Myocardial ischaemia due to arrhythmia and anomalous } \\
\text { coronary artery, echovirus and encephalitis }\end{array}$ & 1 \\
\hline $2(75)$ & 12 years & $\begin{array}{l}\text { Haemophagocytic lymphohistiocytosis with } \\
\text { possible pneumocystis pneumonia infection }\end{array}$ & Natural killer cell leukaemia/lymphoma & 1 \\
\hline $3(4)$ & 13 years & Renal disease, sickle cell, cerebral oedema & $\begin{array}{l}\text { Systemic lupus erythematosus (renal, neural, nodal), } \\
\text { macrophage activation syndrome. Pulmonary aspergillosis }\end{array}$ & 2 \\
\hline $4(7)$ & 11 days & Metabolic disorder causing brain injury & Parechovirus encephalopathy & 2 \\
\hline $5(15)$ & 1 day & $\begin{array}{l}\text { Hypoxic brain injury due to meconium } \\
\text { aspiration and large abdominal } \\
\text { arteriovenous malformation }\end{array}$ & $\begin{array}{l}\text { Hypoxic brain injury due to meconium aspiration, } \\
\text { extrahepatic biliary atresia, hexokinase } 1 \text { deficiency }\end{array}$ & 2 \\
\hline $6(39)$ & 5 months & Out of hospital cardiac arrest & H1N1 myocarditis, pneumonitis and hepatitis & 2 \\
\hline $7(44)$ & 13 days & $\begin{array}{l}\text { Middle cerebral artery (MCA) infarct second- } \\
\text { ary to congenital heart disease (CHD) }\end{array}$ & $\begin{array}{l}\text { MCA infarct secondary to CHD, bronchopneumonia and } \\
\text { pulmonary lymphangiectasia }\end{array}$ & 2 \\
\hline $8(46)$ & 4 months & $\begin{array}{l}\text { Pulmonary hypertension secondary to } \\
\text { emphysematous lung disease and CHD }\end{array}$ & $\begin{array}{l}\text { Respiratory failure secondary to dysmaturity and diffuse } \\
\text { alveolar damage, } \\
\text { filamin A mutation, cardiac valve dysplasia, pyloric stenosis, } \\
\text { ulcerative ileitis }\end{array}$ & 2 \\
\hline $9(51)$ & 1 day & $\begin{array}{l}\text { Ichthyosis, seizures, atrial septal defect, patent } \\
\text { ductus arteriosus, cardiomyopathy, } \\
\text { thrombocytopenia }\end{array}$ & $\begin{array}{l}\text { Cardiomyopathy secondary to congenital glycosylation } \\
\text { disorder, duct plate malformation, ventricular } \\
\text { non-compaction, ichthyosis }\end{array}$ & 2 \\
\hline $10(55)$ & 42 days & $\begin{array}{l}\text { Pulmonary hypoplasia, congenital nephrotic } \\
\text { syndrome }\end{array}$ & Thromboembolism and vasculopathy, myocardial ischaemia & 2 \\
\hline 11(59) & 11 years & Idiopathic pulmonary hypertension & Pulmonary Haemorrhage & 2 \\
\hline $12(61)$ & 2.5 months & $\begin{array}{l}\text { Multiorgan failure due to unknown } \\
\text { inflammatory process/vasculitis }\end{array}$ & Takayasu arteritis & 2 \\
\hline $13(65)$ & 7 months & $\begin{array}{l}\text { Cardiac arrest secondary to mucus plug vs } \\
\text { foreign body }\end{array}$ & Hypoxic brain injury, foetal endocardial fibroelastosis & 2 \\
\hline $14(94)$ & 3 days & Dilated cardiomyopathy and cardiac arrest & Cardiomyopathy secondary to mitochondrial disorder & 2 \\
\hline
\end{tabular}

than that previously reported in the US at 36\% [4]. Autopsy rates have fallen in many parts of the world, with a relatively precipitous fall in consented autopsies in Ireland following public disquiet due to revelations of organ retention in 1999. Adappa et al. reported lack of consent as the primary reason for the reduction in autopsy rates from the period 1994-1996 compared to 2001-2003 [9]. In our institution, the autopsy rate fell by $40 \%$ in the period 2000-2002 in part due to reluctance of families to give consent and also in part by medical staff's reluctance to discuss the prospect with families given the public discussion at the time. The autopsy rate in our unit remained relatively stable throughout the study period; however, the majority of these were performed under the direction of the coroner. Seventy-five cases $(75 \%)$ involved in our study underwent post-mortem after discussion with the coroner.

Whether legally directed or consented by families, it is important that autopsy rates remain at a sufficient level to permit detection of systemic errors in the performance of an institution. It is therefore vital that hospital staff continue to advocate for a high level of post-mortem interrogation of deaths, so that they may be able to reassure the hospital authorities and users of the service that their service continues to provide an appropriate level of care.
To support physicians in pursuing this goal, it is important to acknowledge the limitations of clinical diagnosis. Although we applied an "error" classification tool to describe discrepancies between clinically derived diagnostic conclusions and autopsy findings, this should not be taken to mean that shortcomings in the care delivered have been identified. Rather, such new findings merely serve to highlight the unique role this potent form of investigation plays in furthering our understanding of disease. Previous studies have shown that autopsies add new information in $23-47.5 \%$ of cases, and previously reported major discrepancy rates amongst the paediatric age group have varied but remained approximately $20 \%[3,6,10]$. Our review identifies a major discrepancy in $14.1 \%$ of examinations, a figure derived from the combination of class 1 and class 2 errors. The additional information gained from the class 2 errors in particular contributed towards a complete picture of each patient's overall co-morbidities and aided in explaining the clinical picture leading up to the time of death. In part, this comparatively low figure may reflect the relatively high percentage of patients with congenital heart disease in which either detailed imaging or surgical intervention had been performed prior to the death. It may also reflect improvements in the quality of imaging and other diagnostic 
modalities which underlie secular decreasing discrepancy rates as published, in relation to both paediatric and adult ICU cohorts [11-13].

However, even with these improvements and although many authors have discussed alternatives, we find it difficult to envisage a scenario in which it would be possible to entirely remove the need for post-mortem examinations for the foreseeable future. A dry chart review following the death of a patient can often help opinions coalesce around a likely cause of death. Post-mortem cross-sectional imaging with CT or MR can also provide critical information about the cause of death. Nonetheless, concordance rates with $\mathrm{CT}$ scanning are at best moderate (57.1-83.3\%) [14-17]. In circumstances where imaging is helpful, it is often best used as a means of focusing subsequent invasive post-mortem examination which might potentially be limited to a biopsy of a region of interest rather than full-body examination.

While not detracting from the principal finding that discrepancies remain a feature of post-mortem examinations, it is appropriate to acknowledge some subjectivity in the application of the Goldman error classification system. The authors of this study had some lengthy conversations about many of the individual patients whose clinical care and autopsy findings were reviewed. Indeed, one of the conclusions of the study is the difficulty in applying a relatively rigid Goldman classification of errors to the complex setting of an intensive care unit in which patients frequently have multiple co-morbidities. Instead of identifying single discrepancies that were easily designated as one class or another, the conversations often revolved around the re-evaluation of the relative contribution of the multiple problems already known to afflict an individual patient. Thus, for example, a patient with known congenital heart disease, lung disease associated with prematurity and superimposed sepsis might, after a discussion of the clinical data and post-mortem findings, have a reinterpretation of the relative contributions each of these known findings made to the patient's ultimate demise. As such, even when not detecting a discrepancy per se, the autopsy process contributed to a change in the narrative given to the family by the hospital staff.

The role autopsy plays in arriving at the most in-depth understanding of the factors contributing to death is central to the way post-mortem investigations are communicated in our institution. To facilitate this, where indicated, the pathologist meets with the family close to the time of death to discuss conducting a post-mortem examination. This helps to facilitate questions the family may have regarding the procedure and ensures clarity about the post-mortem process. This open discourse ensures clarity and consistency of information are imparted to the patient's family [18]. Each death in our unit is discussed at a multidisciplinary morbidity and mortality meeting where all teams involved in the patients' care can attend. Post-mortem reports are presented at this multidisciplinary mortality review meeting. Care is discussed and evaluated and an agreed narrative conclusion reached. This considered opinion is then delivered to parents in faceto-face at follow-up, next-of-kin clinics. These afford parents an opportunity to ask questions about the findings and any aspects of care [19]. This integration of post-mortem results into unit morbidity and mortality case discussion, as well as bereavement follow-up with the family, places the autopsy within a continuum of care offered to the patient and their family, rather than as a discrete exercise undertaken by a detached pathologist, and divorced from the patient and staff caring for them. Morbidity and mortality meetings when carried out in a structured manner have been shown to lead to a proportional increase in quality improvement interventions ultimately leading to improved patient care [20]. Postmortems and M\&M conferences are clearly just one component of what should be a systematic, comprehensive and organisation-wide approach to learning from errors.

Our study had a number of limitations. It was retrospective, and although this was largely immaterial in relation to the post-mortem finding, collection and evaluation of such clinical data as is pertinent would be more easily and more comprehensively performed in a prospective fashion. The majority of post-mortem exams reviewed were performed at the direction of the coroner's office. This may limit the generalisability of our findings to exams performed on medical rather than legal grounds. Also assignment of Goldman classification was not blinded or undertaken by medical professionals unaffiliated with our centre. We do not believe these limitations detract from the central findings in this study.

\section{Conclusion}

Our findings show that the autopsy rate at our centre is comparable to that in many other studies at present and is at a sufficient level to detect a proportion of systemic errors in care within our complex PICU environment. The autopsy continued to find a small but significant rate of discrepancy between the pre-mortem clinical interpretation of the cause of death and post-mortem findings. The Goldman classification can present some difficulties in its application due to the user's interpretation of the qualitative data. The classification still holds merit given its wide use and application in studies published to data allowing comparison between similar units. Furthermore, autopsies often provided information that permitted a more nuanced re-evaluation of the contribution of many known co-morbidities as well as identifying other associated anomalies unrelated to the cause of death, but which altered the discussion that ultimately took place between families and hospital staff. As part of our conclusion, we note the $40 \%$ reduction in autopsy rate since 2002 and we offer the recommendation that if any doubt is in place over the clinical 
picture, either a full or targeted post-mortem should be considered. This would benefit both parents and staff who cared for the patient and allow for MDT discussion post-mortem with any new information being shared to provide new insight and closure.

Abbreviations PICU, Paediatric intensive care unit; ICU, Intensive care unit; ECLS, Extracorporeal life support; SARS-CoV-2, Severe acute respiratory syndrome coronavirus-2; CT, Computed tomography; MR, Magnetic resonance

Availability of data Data can be shared upon reasonable request.

Code availability N/A.

Authors' contributions $\mathrm{MO}$ 'R, $\mathrm{MH}$ and $\mathrm{MMcD}$ all contributed towards the study design. MO'R collected data from PICU database and MMcD from the pathology database. All three authors contributed equally towards the results and drafting of the manuscript.

\section{Declarations}

Ethics approval This study, REC reference GEN/879/20, was reviewed by the $\mathrm{CHI}$ at Crumlin Ethics Committee and publication of these clinical audit findings were approved.

Consent to participate Not applicable.

Consent for publication All authors consent to the publication of the manuscript in the European Journal of Paediatrics, should the article be accepted by the editor-in-chief upon completion of the refereeing process.

Competing interests The authors declare no competing interests.

\section{References}

1. Dada MA, Ansari NA (1996) Origins of the postmortem examination in diagnosis. J Clin Pathol 49(12):965-966. https://doi.org/10. 1136/jcp.49.12.965

2. Roberts ISD, Benamore RE, Benbow EW, Lee SH, Harris JN, Jackson A, Mallett S, Patankar T, Peebles C, Roobottom C, Traill ZC (2012) Post-mortem imaging as an alternative to autopsy in the diagnosis of adult deaths: a validation study. Lancet 379:136-142. https://doi.org/10.1016/S0140-6736(11)61483-9

3. Widmann R, Caduff R, Giudici L, Zhong Q, Vogetseder A, Arlettaz R, Frey B, Moch H, Bode PK (2016) Value of postmortem studies in deceased neonatal and pediatric intensive care unit patients. Virchows Arch 470(2):217-223. https://doi.org/10.1007/s00428016-2056-0

4. Basu S, Holubkov R, Dean JM, Meert KL, Berg RA, Carcillo J, Newth CJL, Harrison RE, Pollack MM, Eunice Kennedy Shriver National Institute of Child Health and Human Development Collaborative Pediatric Critical Care Research Network (CPCCRN) (2018) PICU autopsies: rates, patient characteristics, and the role of the medical examiner. Pediatr Crit Care Med 19(12):1137-1145
5. Goldman L, Sayson R, Robbins S, Cohn LH, Bettmann M, Weisberg M (1983) The value of the autopsy in three medical eras. N Engl J Med 308(17):1000-1005

6. Custer JW, Winters BD, Goode V, Robinson KA, Yang T, Pronovost PJ, Newman-Toker DE (2015) Diagnostic errors in the pediatric and neonatal ICU: a systematic review. Pediatr Crit Care Med 16(1):29-36

7. Burton JL, Underwood J (2007) Clinical, educational, and epidemiological value of autopsy. Lancet 369:1471-1480. https://doi. org/10.1016/S0140-6736(07)60376-6

8. Menter T, Haslbauer JD, Nienhold R, Savic S, Hopfer H, Deigendesch N, Frank S, Turek D, Willi N, Pargger H, Bassetti S, Leuppi JD, Cathomas G, Tolnay M, Mertz KD, Tzankov A (2020) Post-mortem examination of COVID19 patients reveals diffuse alveolar damage with severe capillary congestion and variegated findings of lungs and other organs suggesting vascular dysfunction. Histopathology 77(2):198-209. https://doi.org/10.1111/ his. 14134

9. Adappa R, Paranjothy S, Roberts Z, Cartlidge PHT (2007) Perinatal and infant autopsy. Arch Dis Child Fetal Neonatal Ed 92(1):F49 F50. https://doi.org/10.1136/adc.2005.091447

10. von Dessauer B, Velozo L, Benavente C, Bobenrieth F, Bongain J, Irazuzta J (2011) Postmortem studies in the contemporary pediatric intensive care unit. Pediatr Crit Care Med 12(6):617-621

11. Podbregar M, Voga G, Krivec B, Skale R, Parežnik R, Gabršček L (2001) Should we confirm our clinical diagnostic certainty by autopsies? Intensive Care Med 27(11):1750-1755. https://doi.org/10. 1007/s00134-001-1129-x

12. Sonderegger-Iseli K, Burger S, Muntwyler J et al (2000) Diagnostic errors in three medical eras: a necropsy study. Lancet 355:20272031. https://doi.org/10.1016/S0140-6736(00)02349-7

13. Schwanda-Burger S, Moch H, Muntwyler J, Salomon F (2012) Diagnostic errors in the new millennium: a follow-up autopsy study. Mod Pathol 25(6):777-783.

14. Krentz BV, Alamo L, Grimm J, Dédouit F, Bruguier C, Chevallier C, Egger C, da Silva LFF, Grabherr S (2016) Performance of postmortem CT compared to autopsy in children. Int J Legal Med 130(4):1089-1099. https://doi.org/10.1007/s00414-016-1370-Z

15. Noda Y, Yoshimura K, Tsuji S, Ohashi A, Kawasaki H, Kaneko K, Ikeda S, Kurokawa H, Tanigawa N (2013) Postmortem computed tomography imaging in the investigation of nontraumatic death in infants and children. Biomed Res Int 327903:1-5. https://doi.org/ $10.1155 / 2013 / 327903$

16. Sieswerda-Hoogendoorn T, Soerdjbalie-Maikoe V, de Bakker H, van Rijn RR (2014) Postmortem CT compared to autopsy in children; concordance in a forensic setting. Int J Legal Med 128(6): 957-965. https://doi.org/10.1007/s00414-014-0964-6

17. Proisy M, Marchand AJ, Loget P, Bouvet R, Roussey M, Pelé F, Rozel C, Treguier C, Darnault P, Bruneau B (2013) Whole-body post-mortem computed tomography compared with autopsy in the investigation of unexpected death in infants and children. Eur Radiol 23(6):1711-1719. https://doi.org/10.1007/s00330-012-2738-1

18. McDermott M (2004) The continuing decline of autopsies in clinical trials: is there any way back? Arch Dis Child Fetal Neonatal Ed 89(3):F198-F199. https://doi.org/10.1136/adc.2003.045609

19. McDermott MB (2003) Obtaining consent for autopsy. Bmj 327: 804-806. https://doi.org/10.1136/bmj.327.7418.804

20. Cifra CL, Bembea MM, Fackler JC, Miller MR (2016) Transforming the morbidity and mortality conference to promote safety and quality in a PICU. Pediatr Crit Care Med 17(1):58-66. https://doi.org/10.1097/pcc.0000000000000539

Publisher's note Springer Nature remains neutral with regard to jurisdictional claims in published maps and institutional affiliations. 